\title{
Concomitant Production of Hydrogen, Sodium Acetate, and Polymerized Species from Non-Catalytic Ethanol Dehydrogenation
}

\author{
Bárbara B. Cazula, ${ }^{\oplus a, b}$ Eduardo C. Meurer, ${ }^{*, c}$ Alan M. Fortes, ${ }^{a}$ Angelica P. Tonin, ${ }^{c}$ \\ Lázaro J. Gasparrini, ${ }^{a, d}$ Carlos I. Yamamoto ${ }^{e}$ and Helton J. Alves ${ }^{a, b, d}$ \\ ${ }^{a}$ Laboratório de Catálise e Produção de Biocombustíveis (LabCatProBio), \\ Universidade Federal do Paraná (UFPR), R. Pioneiro, 2153, Jardim Dallas, \\ 85950-000 Palotina-PR, Brazil \\ ${ }^{b}$ Programa de Pós-Graduação em Engenharia de Energia na Agricultura, \\ Universidade Estadual do Oeste do Paraná (Unioeste), 85819-110 Cascavel-PR, Brazil \\ ${ }^{c}$ Laboratório FENN de Espectrometria de Massas, Universidade Federal do Paraná(UFPR), \\ 86900-000 Jandaia do Sul-PR, Brazil

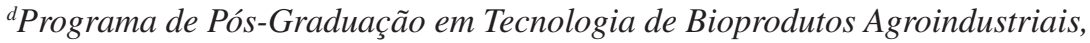 \\ Universidade Federal do Paraná (UFPR), R. Pioneiro, 2153, Jardim Dallas, \\ 85950-000 Palotina-PR, Brazil \\ eLaboratório de Análises de Combustíveis Automotivos (Lacaut), Centro Politécnico, \\ Universidade Federal do Paraná (UFPR), 81531-980 Curitiba-PR, Brazil
}

\begin{abstract}
A detailed study of the production of hydrogen and high added-value liquid products from the ethanol dehydrogenation reaction in the presence of sodium hydroxide $\left(10 \% \mathrm{~m} \mathrm{~m}^{-1}\right)$ was undertaken. Experiments were carried out in a batch reactor under different reaction conditions (temperature of $240{ }^{\circ} \mathrm{C}$ and autogenous pressure between 45 and 72 bar), with analysis of the products obtained in the gas, liquid and solid fractions. The results showed that hydrogen was the major product formed in the gaseous fraction (maximum of $86.9 \%$ ), while sodium acetate was the product in the solid fraction. Studies of the reaction mechanisms confirmed formation of the products identified in the gaseous and solid fractions. Mass spectrometry analyses of the liquid fractions revealed the presence of a series of compounds with molecular masses considerably higher than that of ethanol, which could be explained by the favoring of anionic polymerization reactions, under the experimental conditions employed.
\end{abstract}

Keywords: biomass, dehydrogenation of alcohols, mass spectrometry

\section{Introduction}

The production of fuels from renewable resources has become a major focus of researchers and industry, due to the increasing demand for energy and the need for environmental preservation. ${ }^{1-5}$ Renewable gaseous fuels, such as hydrogen, are among the most promising options for diversification of global energy sources., ${ }^{1,4-7}$ According to the International Energy Agency, ${ }^{8}$ hydrogen is forecast to account for about $18 \%$ of total global energy supply by 2050 , as one of the pillars responsible for an energy transition and reduction of emission of almost 6 gigatons

*e-mail: eduardo.meurer@gmail.com of carbon dioxide into the atmosphere. The production of hydrogen and hydrocarbons by means of the ethanol dehydrogenation reaction is an attractive option, since ethanol is a renewable and readily available fuel. ${ }^{1,4-7,9-11}$

The ethanol dehydration (equation 1) and dehydrogenation (equation 2) reactions are important for producing industrially relevant high added-value compounds from a renewable resource that is widely available. ${ }^{1-6}$ These two reactions can compete, and it is possible to alter the reaction conditions in order to favor formation of the desired product. ${ }^{1-3,6}$ The aldehyde watershift (AWS) reaction (equation 3) can also be used for the production of $\mathrm{H}_{2}$ in the ethanol dehydrogenation process, with acetic acid also being produced. ${ }^{12-14}$ 


$$
\begin{aligned}
& \mathrm{C}_{2} \mathrm{H}_{5} \mathrm{OH} \rightarrow \mathrm{C}_{2} \mathrm{H}_{4}+\mathrm{H}_{2} \mathrm{O} \\
& \mathrm{C}_{2} \mathrm{H}_{5} \mathrm{OH} \rightarrow \mathrm{C}_{2} \mathrm{H}_{4} \mathrm{O}+\mathrm{H}_{2} \\
& \mathrm{C}_{2} \mathrm{H}_{3} \mathrm{OH}+\mathrm{H}_{2} \mathrm{O} \rightarrow \mathrm{CH}_{3} \mathrm{COOH}+\mathrm{H}_{2}
\end{aligned}
$$

The ethanol dehydrogenation reaction, in the presence of catalysts, produces $\mathrm{H}_{2}$ and carboxylates, and is favored by a basic reaction medium. ${ }^{1,6}$ On the other hand, the ethanol dehydration reaction is favored by low $\mathrm{pH}$ and produces ethylene and carboxylates, ${ }^{1,6,15}$ which are usually manufactured industrially by the cracking of hydrocarbons ${ }^{16}$ or by the Fischer-Tropsch synthesis. ${ }^{7,11,17-19}$ As shown in equations 1 and 2, the reactions produce carbon monoxide and $\mathrm{CO}_{2}$, which can be viewed as a problem, from the environmental perspective. ${ }^{1}$

The catalysts most widely used for ethanol dehydrogenation include metals such as $\mathrm{Ni}, \mathrm{Cu}, \mathrm{Co}$, $\mathrm{Cr}$, or $\mathrm{Zn}$ supported on $\mathrm{Al}_{2} \mathrm{O}_{3}, \mathrm{ZrO}_{2}$, or zeolites. ${ }^{5,15,16,20,21}$ However, alternatives that are less expensive and have lower environmental impacts are required for the production of $\mathrm{H}_{2}$ and high added-value compounds from ethanol. Therefore, important topics to be studied include the development of new catalysts that are cheaper and simpler, minimization of $\mathrm{CO}$ and $\mathrm{CO}_{2}$ production, and detailed investigation of the liquid fraction produced in the reaction..$^{1,4,10}$

Sato et al. ${ }^{4}$ used the liquid fraction from the ethanol dehydrogenation reaction performed with $\mathrm{au} / \mathrm{ZrO}_{2}$ catalyst, in a reactor at $513 \mathrm{~K}$ and ambient pressure, as an additive for internal combustion engines. The liquid fraction was studied using high performance liquid chromatography (HPLC), which showed the formation of acetaldehyde, ethyl acetate, methyl ethyl ketone, propanone, and crotonaldehyde. The selectivity towards each product was determined and it was found that longer reaction times led to greater conversion of ethanol to liquid products, with maximum conversion

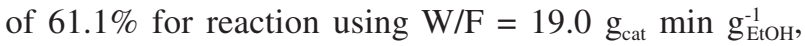
where $\mathrm{W}$ is catalyst weight $(\mathrm{g})$ and $\mathrm{F}$ is flow rate of ethanol $\left(\mathrm{g}_{\mathrm{EtOH}} \mathrm{h}^{-1}\right)$. Longer reaction times led to higher formation of ethyl acetate $(63.1 \%$ selectivity at $\mathrm{W} / \mathrm{F}=19.0)$ and lower formation of acetaldehyde $(28.3 \%$ selectivity at $\mathrm{W} / \mathrm{F}=19.0)$.

Wang et al. ${ }^{6}$ used a computational approach to evaluate catalytic ethanol dehydration and dehydrogenation reactions, employing the molecules $\mathrm{H}_{2} \mathrm{O}, \mathrm{H}_{2} \mathrm{O}_{2}, \mathrm{HF}, \mathrm{NH}_{3}$, $\mathrm{HCOOH}$, and $\mathrm{H}_{3} \mathrm{PO}_{4}$, as well as autocatalytic decomposition of ethanol. It was concluded that a greater presence of basic molecules in the medium significantly favored the ethanol dehydrogenation reaction, leading to higher percentages of $\mathrm{H}_{2}$ and acetaldehyde formation.

Qu et al. ${ }^{1}$ obtained $\mathrm{H}_{2}$ and carboxylates at high purity from the alcohols methanol, ethanol, $n$-butanol, $n$-octanol, $n$-hexadecanol, and isopropanol, in the presence of high concentrations of bases $\left(\mathrm{NaOH}, \mathrm{KOH}, \mathrm{LiOH}, \mathrm{Ca}(\mathrm{OH})_{2}\right.$, and $\left.\mathrm{Mg}(\mathrm{OH})_{2}\right)$. The reaction assays were performed using an alcohol/base ratio of 10:1, in a $\mathrm{Zr}$ autoclave at 493 and $513 \mathrm{~K}$, during periods of 120 and $240 \mathrm{~min}$, at pressures up to 32 bar. The best results were obtained by reacting ethanol and $\mathrm{NaOH}$ at $523 \mathrm{~K}$ for $240 \mathrm{~min}$, resulting in good percentage yields for $\mathrm{H}_{2}$ and solid sodium acetate.

The work of Qu et al. ${ }^{1}$ indicates an attractive option for the production of $\mathrm{H}_{2}$ and high added-value carboxylates, employing a reaction that is simple, relatively inexpensive, and requires only mild temperature conditions, while avoiding $\mathrm{CO}$ and $\mathrm{CO}_{2}$ production. The reaction mechanism proposed is relevant, and consisted of three step mechanism for dehydrogenation reaction whereby the ethanol produced in the third step could again participate in the first step (discussed below), although no detailed analyses were made of the solid and liquid fractions resulting from the ethanol dehydrogenation reaction, with the authors only describing the formation of sodium acetate as a reaction product.

The present work reports the synthesis of $\mathrm{H}_{2}$ and high added-value liquid products from the ethanol dehydrogenation reaction in the presence of $\mathrm{NaOH}$, with detailed study of the gaseous, liquid, and solid fractions resulting from the reaction, based on the work of Qu et al. ${ }^{1}$ A process yield balance was performed in order to determine the best conditions for formation of the product of interest. The solid and liquid fractions were characterized in order to obtain detailed information about the reaction products and to compare them with those expected from reaction mechanisms already reported in the literature.

\section{Experimental}

The reactions were performed in a batch type Teflonlined stainless steel reactor with a useful capacity of $150 \mathrm{~mL}$ (Figure 1), evaluating the influence of reaction time on the yield.

The experiments (R1-R8) were as shown in Table 1. The reaction denoted RB was the experimental blank, without addition of $\mathrm{NaOH}$. The assays were performed using different mass loads, at a temperature of $240^{\circ} \mathrm{C}$, with autogenous pressure in the reactor. The reaction start time was taken to be when the set temperature was reached. At the end of the reaction time, the reactor was left at rest for $12 \mathrm{~h}$, after which the gaseous, liquid, and solid fractions were collected for analysis.

The gaseous fraction was analyzed by gas chromatography, using a C2V-200 instrument (Thermo Scientific) fitted with a thermal conductivity detector (TCD) nano detector and Plot-MS5A (Molecular Sieve 5A) and Bond-U (divinylbenzene type $\mathrm{U}$ ) columns. The liquid fraction was analyzed by mass spectrometry, using a Premier XE system 


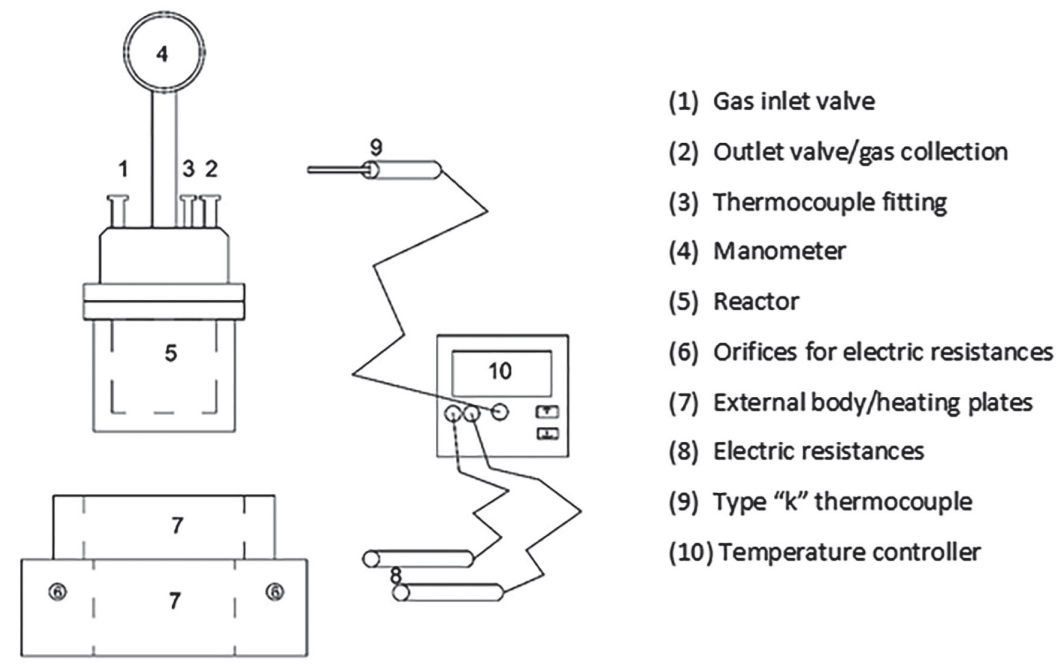

Figure 1. Schematic illustration of the reactor used for the ethanol dehydrogenation reactions: (1) reactor gas inlet valve; (2) gas outlet valve (collection point); (3) thermocouple fitting; (4) manometer pressure gauge; (5) cylindrical Teflon-lined reactor; (6) orifices for attachment of electric resistances; (7) heating plates; (8) electric resistances; (9) type " $\mathrm{k}$ " thermocouple for temperature recording; (10) temperature controller.

(Waters) equipped with a triple quadrupole detector and electrospray ionization (ESI). The samples were analyzed in negative mode, for $m / z$ 10-500, with direct injection after 400 -fold dilution of the crude sample. The solid fraction was analyzed using a Fourier transform infrared absorption (FTIR) spectrum (Model 65, PerkinElmer) fitted with an attenuated total reflection (ATR) accessory, in the range $600-4000 \mathrm{~cm}^{-1}$, with spectral resolution of $0.5 \mathrm{~cm}^{-1}$.

The Gibbs surface energies of the optimized geometries obtained without symmetry restrictions were determined by density functional theory (DFT) calculations at the B3LYP/6-311+G** level, performed using SPARTAN14. ${ }^{22}$ Details of the energies and optimized structures are available from the authors upon request.

\section{Results and Discussion}

The gas chromatography analyses showed that all the reactions produced $\mathrm{H}_{2}$ as the major product (Table 1). The gases ethylene and ethane were also produced in smaller quantities, and traces of $\mathrm{CO}$ and $\mathrm{CO}_{2}$ (lower than $1 \%$ ) were also found (except for the RB reaction).

From comparison of assays R1, R2, and R3, and assays $\mathrm{R} 5$, R6, and R7, which were performed at $240{ }^{\circ} \mathrm{C}$ under autogenous pressure (between 45 and 72 bar), it could be seen that as the reaction time increased, $\mathrm{H}_{2}$ production increased, with consequent reduction in the amount of ethylene produced. The ethanol dehydration reaction leads to the formation of ethylene, which undergoes decomposition (equation 4$)^{7,11}$ in the presence of water, with formation of $\mathrm{CO}$ and $\mathrm{H}_{2}$.

$\mathrm{C}_{2} \mathrm{H}_{4}+\mathrm{H}_{2} \mathrm{O} \rightarrow 2 \mathrm{CO}+4 \mathrm{H}_{2}$

In comparison of reactions $\mathrm{R} 1, \mathrm{R} 2$, and $\mathrm{R} 3$ with reactions $\mathrm{R} 5, \mathrm{R} 6$, and $\mathrm{R} 7$, respectively, it could be seen that a decrease of the ethanol load in the reactor led to a decrease in the $\mathrm{H}_{2}$ content, since hydrogen production was related

Table 1. Descriptions of the ethanol dehydrogenation reaction assays in the presence of $\mathrm{NaOH}$

\begin{tabular}{|c|c|c|c|c|c|c|c|c|}
\hline \multirow[b]{2}{*}{ Reaction } & \multicolumn{4}{|c|}{ Experiments } & \multicolumn{4}{|c|}{ Gaseous compositions / \% } \\
\hline & Ethanol / g & $\mathrm{NaOH} / \mathrm{g}$ & Ethanol: $\mathrm{NaOH}$ & $\begin{array}{l}\text { Reaction time } \\
/ \mathrm{min}\end{array}$ & $\mathrm{H}_{2}$ & $\mathrm{CO}_{2}$ & Ethylene & Ethane \\
\hline $\mathrm{R} 1$ & 30 & 3.0 & $10: 1$ & 240 & 81.0 & 0.0 & 17.8 & 1.2 \\
\hline R2 & 30 & 3.0 & $10: 1$ & 120 & 76.8 & 0.1 & 22.9 & 0.2 \\
\hline R3 & 30 & 3.0 & $10: 1$ & 30 & 63.9 & 0.0 & 31.3 & 4.6 \\
\hline $\mathrm{R} 4$ & 15 & 1.5 & $10: 1$ & 240 & 86.9 & 0.7 & 12.3 & 0.1 \\
\hline R5 & 20 & 3.0 & ca. $7: 1$ & 240 & 69.9 & 0.0 & 21.2 & 8.6 \\
\hline R6 & 20 & 3.0 & ca. $7: 1$ & 120 & 72.4 & 0.0 & 27.4 & 0.1 \\
\hline R7 & 20 & 3.0 & ca. $7: 1$ & 30 & 56.4 & 0.0 & 43.5 & 0.1 \\
\hline R8 & 20 & 2.0 & $10: 1$ & 30 & 85.1 & 0.4 & 14.4 & 0.1 \\
\hline $\mathrm{RB}$ & 30 & 0.0 & - & 240 & 55.1 & 39.8 & 5.1 & 0.0 \\
\hline
\end{tabular}


to the amount of ethanol available for dehydrogenation (equation 2). ${ }^{3,5-7,11,23}$ At the same time, the ethylene content increased, due to shift of equation 4 in the direction favoring product formation.

The amount of ethane produced in the assays ranged from 0.1 to $8.6 \%$. The highest percentages of ethane in the final composition were found for the reactions at higher pressures and temperatures, and with longer reaction times.

The high presence of $\mathrm{CO}_{2}$ as a reaction product in the RB assay, performed in the absence of $\mathrm{NaOH}$, was due to favoring of the ethanol dehydration reaction (equation 1), ${ }^{3,5-7,11,23}$ which occurs preferentially in more acidic media. The $\mathrm{CO}$ formed as a product of ethylene decomposition (equation 4) can react with water molecules present in the medium, undergoing a shift reaction resulting in the formation of $\mathrm{CO}_{2}$ and $\mathrm{H}_{2}$ (equation 5). ${ }^{7,11}$

$$
\mathrm{CO}+\mathrm{H}_{2} \mathrm{O} \rightarrow \mathrm{CO}_{2}+\mathrm{H}_{2}
$$

An experiment was performed using a lower $\mathrm{NaOH}$ content (reaction R8), which resulted in substantially higher $\mathrm{H}_{2}$ production (85.1\%), compared to reaction $\mathrm{R} 7$ (56.3\%), with a consequent significant reduction of the ethylene content, corroborating the results discussed above. The effect of the reagent load in the reactor was evaluated in assay R4, maintaining the same parameters as assay R1, but with half the load. The production of hydrogen increased, achieving the highest value found in this work (86.9\%), accompanied by lower production of secondary products such as ethylene and $\mathrm{CO}_{2}$, since the reactions shown in equations 1, 4 and 5 were not favored. The result showed that more diluted solution for the reactants favor the $\mathrm{H}_{2}$ production, since a positive solvent effect seems to take place on $\mathrm{H}_{2}$ production in detrimental of ethylene formation. To form $\mathrm{H}_{2}$ equations 3, 4 and 5 showed the use of water, and to form ethylene the product was water, since water increase on more diluted solution, then the dehydration is less favored and $\mathrm{H}_{2}$ formation is more favored.
Considering reactions R1, R8, and R4, performed using reagent loads of 33, 22 and $16.5 \mathrm{~g}$, respectively, with an ethanol/NaOH molar ratio of 10:1, it could be concluded that lower liquid loads led to larger gaseous fraction volumes (comparing reactions R8 and R4), with higher percentages of $\mathrm{H}_{2}$.

Reactions R4 and R8, which presented the highest percentages of $\mathrm{H}_{2}$, and reaction $\mathrm{RB}$, which showed the lowest percentage of $\mathrm{H}_{2}$ produced, were selected for a more detailed study involving the volume and mass balance of the gaseous products. Table 2 shows the initial and final masses of the liquid and solid fractions of the selected reactions.

It can be seen from Table 2 that $\mathrm{NaOH}$ influenced the reaction yield, since the absence of base in the medium resulted in low production of gaseous products. The lower occupation of the reactor by the (liquid) reactants in reaction R4 left a larger volume available for occupation by the gaseous phase. According to the Le Chatelier principle, considering the existing chemical equilibrium, there was production of a larger gas volume $(1.2 \mathrm{~L})$, with greater conversion of ethanol to products. In the case of reaction $\mathrm{R} 8$, the opposite occurred and a smaller gaseous fraction was produced $(0.35 \mathrm{~L})$.

From the masses of the liquid and solid fractions and the gas volumes produced in the reactions of the second block of experiments (Table 2), it was possible to determine which of the conditions employed (R4 or R8) resulted in the highest production of each fraction, in order to favor generation of the product of interest. It can be seen that reaction R4 produced a larger gaseous volume, together with higher variability of the solid and liquid masses. This indicated that the conditions of reaction R4 favored the generation of gaseous products, while the conditions of reaction R8 favored greater production of the solid and liquid fractions. Reaction RB, performed in the absence of base, presented the highest solid and liquid fractions yield.

$\mathrm{Qu}$ et al. ${ }^{1}$ proposed a sequence of three steps for the ethanol dehydrogenation reaction, whereby the ethanol produced in the third step could again participate in the first

Table 2. Yields and compositions of the gaseous fractions collected in assays RB, R4 and R8

\begin{tabular}{|c|c|c|c|c|c|c|c|}
\hline \multicolumn{8}{|c|}{ Composition of solid, liquid and gas } \\
\hline \multicolumn{3}{|c|}{ Solid and liquid fraction } & \multicolumn{5}{|c|}{ Gaseous fraction } \\
\hline Reaction & Initial & Final & Gas / L & $\mathrm{H}_{2}$ & $\mathrm{CO}_{2}$ & Ethylene & Ethane \\
\hline $\mathrm{RB}$ & $\begin{array}{l}30.0 \mathrm{~g} \\
100 \%\end{array}$ & $\begin{array}{l}28.0 \mathrm{~g} \\
93.3 \%\end{array}$ & 0.05 & $\begin{array}{c}0.027 \mathrm{~L} \\
55.1 \%\end{array}$ & $\begin{array}{l}0.02 \mathrm{~L} \\
39.8 \%\end{array}$ & $\begin{array}{c}0.003 \mathrm{~L} \\
5.1 \%\end{array}$ & $\begin{array}{l}- \\
-\end{array}$ \\
\hline R4 & $\begin{array}{l}16.5 \mathrm{~g} \\
100 \%\end{array}$ & $\begin{array}{l}13.2 \mathrm{~g} \\
80.0 \%\end{array}$ & 1.20 & $\begin{array}{l}1.04 \mathrm{~L} \\
86.9 \%\end{array}$ & $\begin{array}{c}0.009 \mathrm{~L} \\
0.7 \%\end{array}$ & $\begin{array}{l}0.15 \mathrm{~L} \\
12.3 \%\end{array}$ & $\begin{array}{c}0.001 \mathrm{~L} \\
0.1 \%\end{array}$ \\
\hline R8 & $\begin{array}{l}22.0 \mathrm{~g} \\
100 \%\end{array}$ & $\begin{array}{l}19.9 \mathrm{~g} \\
90.5 \%\end{array}$ & 0.35 & $\begin{array}{l}0.29 \mathrm{~L} \\
85.1 \%\end{array}$ & $\begin{array}{c}0.009 \mathrm{~L} \\
0.4 \%\end{array}$ & $\begin{array}{l}0.05 \mathrm{~L} \\
14.4 \%\end{array}$ & $\begin{array}{c}0.001 \mathrm{~L} \\
0.1 \%\end{array}$ \\
\hline
\end{tabular}


1

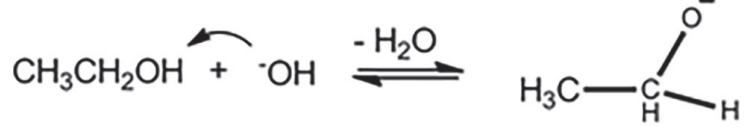

2

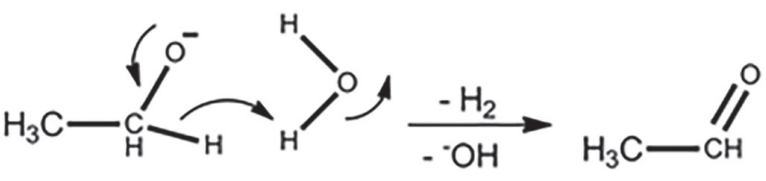

3
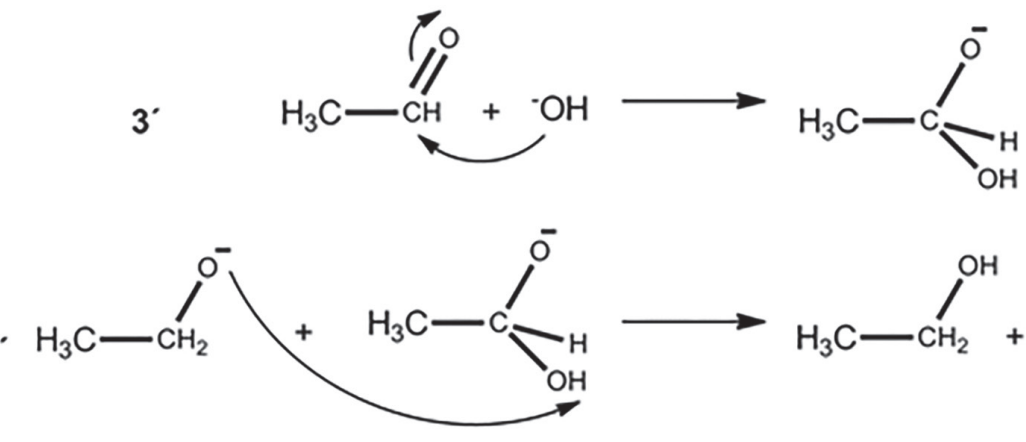

$3^{\prime}$

…<smiles>CC(=O)CC[C@@H](O)C(C)=O</smiles><smiles>CC[C+]C([O-])O</smiles>

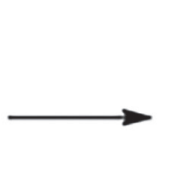<smiles>CC(=O)[O-]</smiles><smiles>CCOC</smiles>

$3 \cdots$
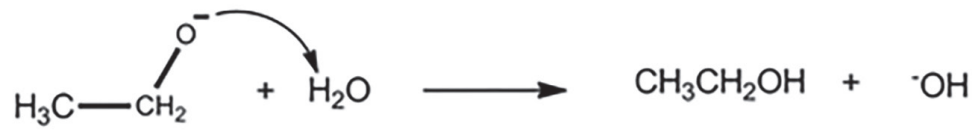

Figure 2. Detailed mechanism proposed by Qu et al. ${ }^{1}$ for the ethanol dehydrogenation reaction with $\mathrm{NaOH}$.

step. The mechanism starts with an acid-base reaction in which hydroxide deprotonates ethanol, with formation of ethoxide and water (Figure 2). In the second step, reaction between ethoxide and water produces acetaldehyde, hydroxide, and hydrogen. The third step consists of reaction between acetaldehyde and hydroxide, forming a nucleophilic addition intermediate, which was suggested to be deprotonated by the alkoxide present in the solution, forming a doubly charged anion (a Canizzaro intermediate), which then reacts with acetaldehyde to form acetate and ethanol. According to the proposed mechanism, a hydride is transferred to acetaldehyde by the Canizzaro intermediate, forming an alkoxide that can be protonated to produce ethanol. The ethanol produced in the third step can then participate in the first step. The authors suggested that $\mathrm{H}_{2}$ formation occurs in the second step, while the third step involves the formation of acetate, without $\mathrm{H}_{2}$ formation.

In Figure 3 we suggested another possible reaction pathway, not covered in Figure 2, that may take place, since neutral ethanol may be present in solution and the first step is equilibrium. The proposed mechanism showed that ethanol may undergo direct dehydrogenation to form the aldehyde, as an alternative to step 2 of Figure 2. Figure 4 shows two other possibilities starting from acetaldehyde. In the first, acetaldehyde reacts with water to form acetic acid, which is subsequently deprotonated in highly basic medium, forming acetate. In the second reaction pathway, acetaldehyde reacts with hydroxide to form acetate. Both mechanisms are associated with the formation of hydrogen. These mechanisms were proposed with ethanol consumption and, based on that, we observe acetate formation and subsequent polymerization, to propose that the reaction go in a pathway without reform ethanol.

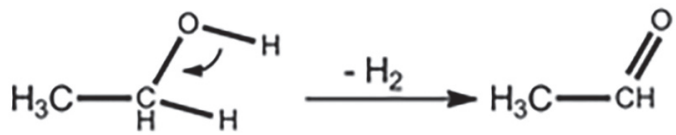

Figure 3. Proposed reaction for the formation of acetaldehyde without hydrogen formation.

Considering the possible reactions shown in Figures 3 and 4 , it can be seen that hydrogen formation could also arise from the step involving the formation of acetate 
(a)

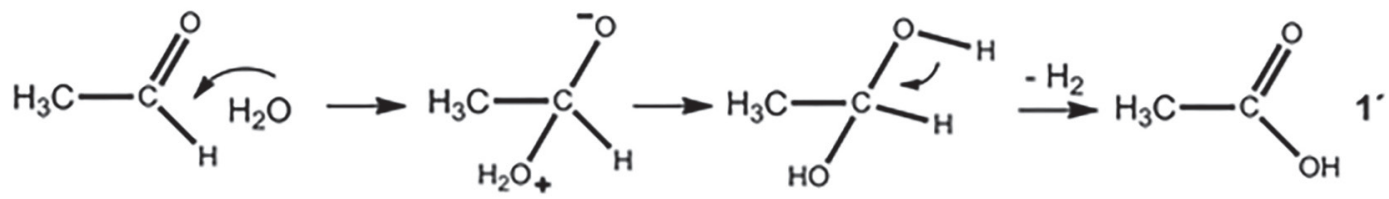

(b)<smiles>CC(=O)CCCCOC(C)CO</smiles>

Figure 4. Proposed reactions for the formation of acetate: (a) reaction with water and several steps with formation of hydrogen; (b) reaction with hydroxide and formation of hydrogen.

from acetaldehyde, and the results of isotopic labeling experiments undertaken by Qu et al. ${ }^{1}$ did not exclude this possibility. In order to obtain further information about the possible mechanisms, ab initio B3LYP/6-311+G** calculations of the Gibbs surface energy (Figure 5) were performed, using the energies for the different mechanisms shown in Figures 3 and 4 (mechanisms 1, 1', and 2'), as well as those proposed by Qu et al. ${ }^{1}$ (mechanisms 2 and $\left.3^{\prime}\right)$. It should be noted that in the case of 3', only the initial and final products of the step were considered.

It can be seen that step 1 is thermodynamically more favorable than step 2, although both can occur in reactors operated at high temperature and pressure. Reactions 1' and 2 ' form the same product and present high exothermicity, showing that it is possible to obtain hydrogen using these routes. The energy difference between steps 2 ' and $3^{\prime}$ is small, suggesting that there could be a mixture of various reactions producing hydrogen.

This behavior, with several reactions occurring at the same time, was corroborated by the mass spectrometry analyses of the liquid fractions collected in the experiments. A comparison of the liquid phase compounds identified in experiments R1, R4, R7 and R8 is shown in Table 3. It can be seen that the results obtained for assays R4 and R8 were very similar.

The mass spectrometry analyses of the liquid fractions for reactions R4 and R8, shown in Figures 6a and 6b, respectively, evidenced the presence of acetate $(\mathrm{m} / \mathrm{z}, 59)$, glycolate $(\mathrm{m} / \mathrm{z}, 75)$, crotonate $(\mathrm{m} / \mathrm{z} \mathrm{85})$, and oxooctanoate $(\mathrm{m} / \mathrm{z}$ 139), in addition to unidentified ions with $\mathrm{m} / \mathrm{z} 167$ and $\mathrm{m} / \mathrm{z}, 183$ (for R4), and $\mathrm{m} / \mathrm{z}, 183$ and 291 (for R8). In order to identify these ions, experiments were performed using collision-induced dissociation (CID), selecting the ion obtained in the experiment, and fragmenting it with argon. The MS/MS spectrum obtained for each compound was compared to the MassBank of North America database. ${ }^{24}$ It should be highlighted that no ethanol was detected in any of the liquid phase samples obtained after the reactions, indicating that the entire mass of ethanol contained in the reactor was converted into reaction products.

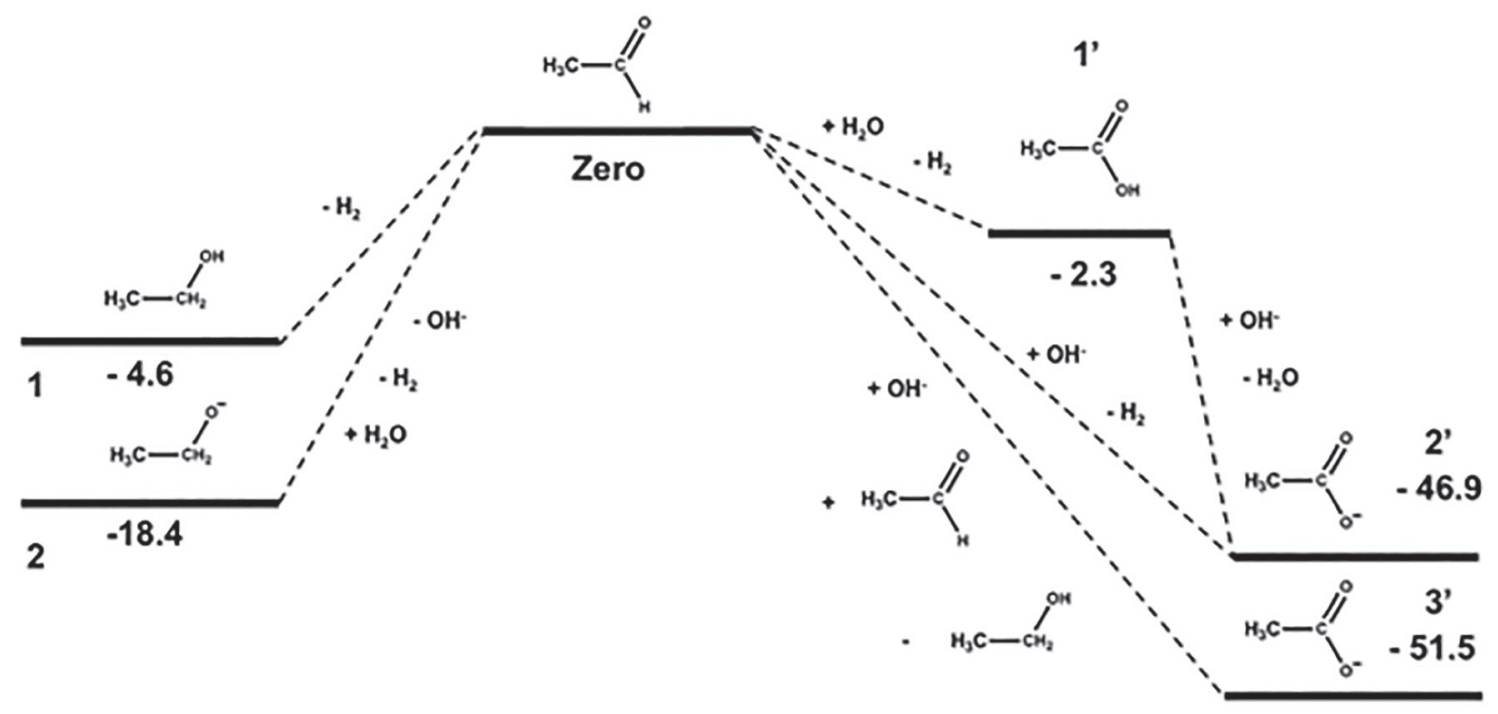

Figure 5. Gibbs surface energies for the possible pathways of the reaction between ethanol and sodium hydroxide, showing steps 1, 1', and 2', proposed in the present work, and reactions 2 and 3', proposed by Qu et al. ${ }^{1}$ 
Table 3. Compositions of the liquid fractions obtained in selected experiments

\begin{tabular}{lcccccc}
\hline Reaction & \multicolumn{3}{c}{ Identified compounds $(\mathrm{m} / \mathrm{z})$} & \multicolumn{2}{c}{ Other compounds } \\
\cline { 2 - 6 } & 59 & 75 & 85 & 129 & 139 & 183,237 \\
\hline R1 & - & $\times$ & $\times$ & $\times$ & $\times$ & 167,183 \\
R4 & $\times$ & $\times$ & - & - & - & $205,337,362,390$ \\
R7 & - & - & $\times$ & - & $\times$ & 183,291 \\
R8 & $\times$ & $\times$ & & & - & $\times$ \\
\hline
\end{tabular}

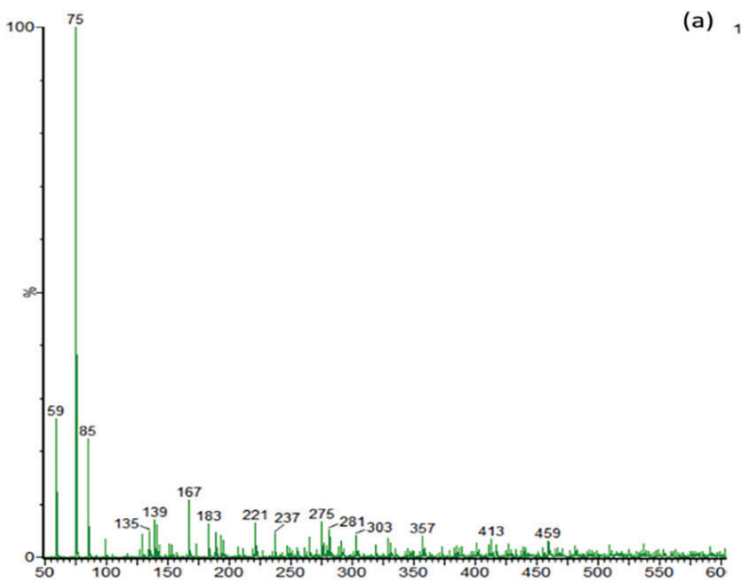

(a)

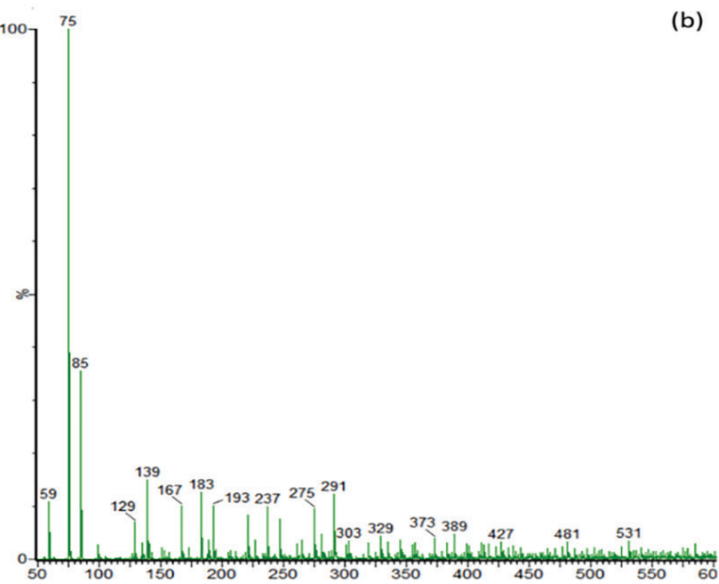

Figure 6. Mass spectra of the samples obtained in experiments R4 (a) and R8 (b).

The carbon chains corresponding to the identified compounds (Figure 7) were even-numbered, with the exception of glycolate $(\mathrm{m} / \mathrm{z}, 75)$, suggesting that these species may have been formed by anionic polymerization reactions. Such polymerization reactions could have been favored by the high concentration of $\mathrm{NaOH}$ in the medium, as well as by the high temperature employed. The temperature and pressure conditions could also have favored the rupture of polymer molecules, leading to the formation of glycolate, which possesses three carbons in its chain. ${ }^{25}$

Infrared spectroscopy analysis was applied to one of the solid fractions collected from the reactions, since all the<smiles>CC(=O)[O-]</smiles><smiles>CC(C)([O-])O</smiles><smiles>C/C=C/C(=O)[O-]</smiles>

Acetate $(\mathrm{m} / \mathrm{z} 59)$ 2-hydroxypropan-2-olate

(2E)-but-2-enoate

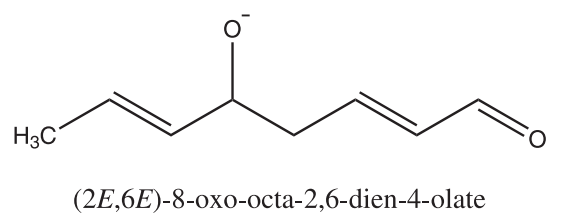

Figure 7. Structures of molecules identified in the mass spectrometry analyses of the liquid fractions obtained in experiments R4 and R8. solid fractions were visually similar. The infrared spectrum is shown in Figure 8. All the bands present indicated that the sample corresponded to sodium acetate, as expected according to the reaction mechanism (Figure 2). Qu et al. ${ }^{1}$ also found pure sodium acetate as the solid product of ethanol dehydrogenation reactions in the presence of $\mathrm{NaOH}$, identified by the authors using FTIR.

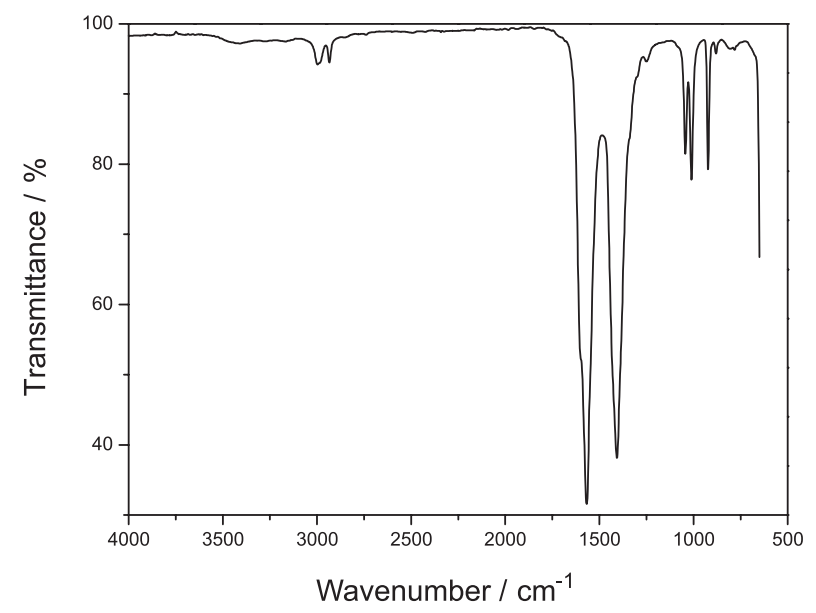

Figure 8. Infrared spectrum of the solid fraction resulting from the reaction.

Bands at 2996 and $2934 \mathrm{~cm}^{-1}$ corresponded to $\mathrm{C}-\mathrm{H}$ bonds of the carbon chain and the methyl group, related 
to carbons with $\mathrm{sp}^{3}$ hybridization. Peaks at 1568 and $1408 \mathrm{~cm}^{-1}$ could be attributed to the carbonyl bond, with two peaks being detected due to the two resonance structures present. Peaks at 1042, 1012 and $924 \mathrm{~cm}^{-1}$ were assigned to stretching of the $\mathrm{C}-\mathrm{O}$ bond, while a peak initiated to $650 \mathrm{~cm}^{-1}$ corresponded to the bond with sodium. ${ }^{23,26}$ The band at $650 \mathrm{~cm}^{-1}$ is not completely observed due to the limit of the instrument used for the analysis.

\section{Conclusions}

This work presents a reaction pathway for the dehydrogenation of ethanol in the presence of $\mathrm{NaOH}$, performed at $240{ }^{\circ} \mathrm{C}$ under autogenous pressure varying between 45 and 72 bar, without the use of a catalyst. This pathway enabled conversion of all the ethanol added to the reactor, leading to the formation of several high added-value products in the gaseous, liquid, and solid phases at the end of the reaction. The gaseous phase was composed mainly of $\mathrm{H}_{2}$ (maximum of $86.9 \%$ ) and ethylene, while the solid fraction consisted exclusively of sodium acetate. Different mechanisms for the production of molecular hydrogen and acetate were compared using $a b$ initio calculations, together with the experimental results, which revealed the complexity of the reactions. Analysis of the liquid fraction evidenced the formation of compounds with molecular masses much higher than that of ethanol, which were produced by anionic polymerization reactions favored by the high temperature and the high concentration of $\mathrm{NaOH}$ in the medium. The different reaction conditions employed for the ethanol dehydrogenation led to variation of the gaseous phase produced, in terms of both its volume and its composition, hence demonstrating the versatility of this route for the selection of products of interest. The studies carried out in the article reveal a relevant and innovative theme bringing with it aspects that contribute to a better understanding of the non-catalytic dehydrogenation reaction of ethanol.

\section{Acknowledgments}

This work has been supported by the Companhia Paranaense de Energia-COPEL research and technological development program, through the PD 2866-0470/2017 project, regulated by ANEEL.

\section{References}

1. Qu, Y. C.; Wei, X. L.; Zuo, Y.; Xu, Q.; Yan, S. Z.; Zhang, Y.; Fu, Y.; Int. J. Hydrogen Energy 2014, 39, 13136.

2. Li, X. N.; Peng, S. S.; Feng, L. N.; Lu, S. Q.; Ma, L. J.; Yue, M. B.; Microporous Mesoporous Mater. 2018, 261, 44.
3. Cortright, R. D.; Davda, R. R.; Dumesic, J. A.; Nature 2002, 418, 964.

4. Sato, A. G.; Biancolli, A. L. G.; Paganin, V. A.; da Silva, G. C.; Cruz, G.; dos Santos, A. M.; Ticianelli, E. A.; Int. J. Hydrogen Energy 2015, 40, 14716.

5. Tayrabekova, S.; Mäki-Arvela, P.; Peurla, M.; Paturi, P.; Eränen, K.; Ergazieva, G. E.; Aho, A.; Murzin, D. Y.; Dossumov, K.; C. R. Chim. 2018, 21, 194.

6. Wang, Y.; Tang, Y.; Shao, Y.; J. Mol. Graphics Modell. 2017, 76,521 .

7. Santacesaria, E.; Carotenuto, G.; Tesser, R.; Di Serio, M.; Chem. Eng. J. 2012, 179, 209.

8. International Energy Agency (IEA); Technology Roadmap-Hydrogen and Fuel Cells; International Energy Agency OECD/IEA, 2015, 81f, available at https:// www.iea.org/publications/freepublications/publication/ TechnologyRoadmapHydrogenandFuelCells.pdf accessed in June 2019.

9. Ail, S. S.; Dasappa, S.; Renewable Sustainable Energy Rev. 2016, 58, 267.

10. Hou, T.; Zhang, S.; Chen, Y.; Wang, D.; Cai, W.; Renewable Sustainable Energy Rev.. 2015, 44, 132.

11. Ni, M.; Leung, D. Y. C.; Leung, M. K. H.; Int. J. Hydrogen Energy 2007, 32, 3238.

12. Brewster, T. P.; Ou, W. C.; Tran, J. C.; Goldberg, K. I.; Hanson, S. K.; Cundari, T. R.; Heinekey, D. M.; ACS Catal. 2014, 4, 3034.

13. Ou, W. C.; Cundari, T. R.; ACS Catal. 2015, 5, 225.

14. Brewster, T. P.; Goldberg, J. M.; Tran, J. C.; Heinekey, D. M.; Goldberg, K. I.; ACS Catal. 2016, 6, 6302.

15. Rodrigues, C. P.; Zonetti, P. C.; Silva, C. G.; Gaspar, A. B.; Appel, L. G.; Appl. Catal., A 2013, 458, 111.

16. Zhang, M.; Yu, Y.; Ind. Eng. Chem. Res. 2013, 52, 9505.

17. Ahn, S. J.; Yun, G. N.; Takagaki, A.; Kikuchi, R.; Oyama, S. T.; Sep. Purif. Technol. 2018, 194, 197.

18. Shi, B.; Jin, C.; Appl. Catal., A 2011, 398, 54.

19. Schneider, J.; Struve, M.; Trommler, U.; Schlüter, M.; Seidel, L.; Dietrich, S.; Rönsch, S.; Fuel Process. Technol. 2018, 170, 64.

20. Yusuf, S.; Neal, L.; Haribal, V.; Baldwin, M.; Lamb, H. H.; Li, F.; Appl. Catal., B 2018, 232, 77.

21. Wang, J.; Li, X.; Zheng, J.; Cao, J.; Hao, X.; Wang, Z.; Abudula, A.; Guan, G.; Energy Convers. Manage. 2018, 164, 122.

22. Shao, Y.; Molnar, L. F.; Jung, Y.; Kussmann, J.; Ochsenfeld, C.; Brown, S. T.; Gilbert, A. T. B.; Slipchenko, L. V.; Levchenko, S. V.; O’Neill, D. P.; DiStasio, R. A.; Lochan, R. C.; Wang, T.; Beran, G. J. O.; Besley, N. A.; Herbert, J. M.; Yeh Lin, C.; Van Voorhis, T.; Hung Chien, S.; Sodt, A.; Steele, R. P.; Rassolov, V. A.; Maslen, P. E.; Korambath, P. P.; Adamson, R. D.; Austin, B.; Baker, J.; Byrd, E. F. C.; Dachsel, H.; Doerksen, R. J.; Dreuw, A.; Dunietz, B. D.; Dutoi, A. D.; Furlani, T. R.; Gwaltney, S. R.; Heyden, A.; Hirata, S.; Hsu, C. P.; Kedziora, G.; 
Khalliulin, R. Z.; Klunzinger, P.; Lee, A. M.; Lee, M. S.; Liang, W.; Lotan, I.; Nair, N.; Peters, B.; Proynov, E. I.; Pieniazek, P. A.; Min Rhee, Y.; Ritchie, J.; Rosta, E.; David Sherrill, C.; Simmonett, A. C.; Subotnik, J. E.; Lee Woodcock, H.; Zhang, W.; Bell, A. T.; Chakraborty, A. K.; Chipman, D. M.; Keil, F. J.; Warshel, A.; Hehre, W. J.; Schaefer, H. F.; Kong, J.; Krylov, A. I.; Gill, P. M. W.; Head-Gordon, M.; Phys. Chem. Chem. Phys. 2006, 8, 3172.
23. Mattos, L. V.; Jacobs, G.; Davis, B. H.; Noronha, F. B.; Chem. Rev. 2012, 112, 4094.

24. MassBank of North America; available at http://mona.fiehnlab. ucdavis.edu/ accessed on September 10, 2018.

25. Machado, F.; Lima, E. L.; Pinto, J. C.; Polímeros 2007, 17, 166.

26. Atomic Spectra Database-NIST; available at https://www.nist. gov/pml/atomic-spectra-database, accessed on May 14, 2018.

Submitted: November 30, 2018

Published online: June 18, 2019 